\title{
Some Tasting Notes on Year-Old Sushi: Funazushi, Japan's Most Ancient and Potentially Its Most Up-to-Date Sushi
}

\begin{abstract}
Funazushi, a fermented food made with crucian carp, is often described as Japan's most ancient form of sushi. This article evaluates these historical claims and offers some tasting notes, exploring traditional versions of the dish and new interpretations that offer a possible future for sushi.

I could never write a global history of sushi without having eaten what has been called the most "ancient form" of sushi, the
\end{abstract}

\section{Funazushi within the History of Sushi in Japan}

Funazushi is sushi made from funa, crucian carp, native to Lake Biwa, Japan's largest freshwater lake, which Shiga Prefecture surrounds. There are three species of crucian carp found in Lake Biwa: gengorobuna (Carassius cuvieri), ginbuna (Carassius langsdorfii), and nigorobuna (Carassius auratus grandoculis). Nigorobuna, a type of crucian carp most closely resembling a goldfish, is the variety now preferred for funazushi (Shiga no Shoku Bunka Kenkyūkai 2011: 16, 26-27).

In contrast to the more widely known types of sushi such as the hand-formed nigirizushi that features slices of fish and seafood pressed on top of rice, and sushi rolls (makizushi) that combine various ingredients and rice in a seaweed wrapper, funazushi is a fermented food. Nigirizushi and makizushi are best consumed right after they are made, but funazushi undergoes a period of fermentation of at least six months and up to several years. The antecedents for funazushi date back to at least the eighth century in Japan, and sushi made by that method of fermentation, called narezushi, was what defined sushi in Japan until the early modern period (1600-1868) when ingredients such as sake, the lees from sake making, and vinegar were added to rice to hasten the fermentation process and eventually eliminate it entirely. Makizushi and nigirizushi, which use rice flavored with vinegar, salt, and usually sugar, were invented in the late eighteenth and early nineteenth centuries respectively. By that point, sushi funazushi found in Shiga Prefecture (Hosking 1996: 43). So on a recent trip to Japan I set aside two days to try to eat as much funazushi as possible. This proved to be challenging for many reasons, not the least of which was the taste of funazushi, which many people find disagreeable. What I learned from the experience was less about sushi's past than a possibility for sushi's future.

no longer designated a method to preserve fish but a means to serve fish with flavored rice. While this flavored rice dish is what defines sushi globally today, older forms of narezushi still exist in Japan as "local sushi," and the funazushi of Shiga Prefecture is the representative example.

Funazushi has a distinct sour taste and that might have been the origin of the word sushi in Japan. According to one hypothesis that dates to at least the end of the seventeenth century, the Japanese word "sushi" was derived from the word sui, meaning sour (Hibino 1997: 15). An ancient Chinese way of writing sushi with the character 䰻 pronounced $z h a$, as found in the secondcentury dictionary Expositor of Names (Shiming), combines the character for fish (魚) with the one for vinegar (乍) and defines zha as a pickled product made from rice and fish (Huang 2000: 384). In Japan, the first written references to sushi date to the eighth century (Ōkawa 2008: 57-58).

Modern sushi has a very slight sour taste because the rice is flavored with vinegar. However, vinegar became a sushi ingredient only in the seventeenth century around the time that Japanese philologists theorized that the Japanese word sushi took its name from its sour taste (Hibino 1997: 89). Earlier forms of sushi, of which funazushi is a modern example, derive their sour taste from lactic acid fermentation.

While rice is central to nigirizushi and makizushi to the point that some sushi experts differentiate the quality of sushi restaurants based largely on how well the rice is prepared, rice plays a more essential role in sushi made with lactic acid 
fermentation (Hayakawa 2009: 29). Rice contains starch that breaks down into glucose when it is soaked in water. Lactic acid bacteria feed on the glucose to produce lactic acid, and lactic acid transforms animal proteins. The bacteria act as a preservative by lowering the $\mathrm{pH}$ of the perishable food to inhibit the growth of microbes that could cause diseases or could otherwise contaminate the food. Lactic acid also imparts a tart flavor, and lactic acid fermentation is the reason why yoghurt has its slightly sour taste (McGee 2004: 44-45; Huang 2000: 380 ). If the process of lactic acid fermentation is allowed to go on long enough, the proteins in animal or fish flesh break down into tasty amino acids and even the bones will become soft enough to eat (Matsushita 1996: 40). In contrast to sushi that rely on vinegar and are best eaten immediately after they are made, lactic acid fermentation takes time. Some examples of lactic acid sushi can take up to two years or more to reach their peak flavor (Shinoda 2002: 23). One of these is funazushi, which can be made in a few months, but three- or five-year-old examples are especially prized (Okumura 2002: 42).

\section{Preparing Funazushi}

Funazushi is often described as an "ancient" form of sushi, but the recipe for funazushi has changed considerably in the last centuries. According to sushi scholar Hibino Terutoshi, the modern recipe for funazushi is only a century or more old, with the first recorded version dating from 1910 (Hibino 1999: 34). To understand how the recipe has changed over time, we can compare early modern and modern versions (ancient and medieval recipes for the dish do not survive).

An early modern version of funazushi appears in the anonymous cookbook Assembly of Standard Cookery Writings (Gōrui nichiyō ryōrishō) published in 1689, which shows how a dish named for the province Gōshū (an older name for Shiga Prefecture) was to be prepared.

\section{THE FUNAZUSHI OF GŌSHU}

Ferment this in mid-winter. Take off the gills and remove the internal organs from them, and flatten the head of the fish. Pile a large amount of salt on a tray and press both sides of the fish on the salt. Just coat the fish with salt and it is ready to be made into sushi. Steam glutinous brown rice and allow it to cool, then mix in some salt for flavoring. Pack the fish [in a pickling bucket] with a lot of rice. [Using a heavy stone on the lid] make sure to apply considerable pressure at the start, but after twenty days, the weight should be lightened as in a typical sushi recipe. If everything turns out well after seven days the sushi will last indefinitely. By summer or autumn of the next year, the taste will be ideal, and the bones will also be soft. When removing the sushi, take off the weight and pour off the water on top of the lid, then readjust the shape of the rice and the fish inside the barrel before replacing the lid and weight stone; cover again with water as before. (Issunsha 1985: 171)
The recipe in Assembly of Standard Cookery Writings indicates that funazushi should be made from fresh fish in the winter as opposed to salt-cured fish in the summer, which is the way funazushi is made today. The use of brown rice is also remarkable, as other sushi recipes in Assembly of Standard Cookery Writings call for polished rice (Issunsha 1985: 170). The consensus among scholars is that funazushi today may use lactic acid fermentation as did ancient sushi, but the modern recipe is quite different from the dish created in the ancient, medieval, or early modern periods (Hashimoto 2016).

The key points of funazushi preparation today can be understood from a family recipe from the Sugimoto household from the city of Nagahama in Shiga Prefecture. The Sugimoto family has worked as fishermen in Lake Biwa for generations.

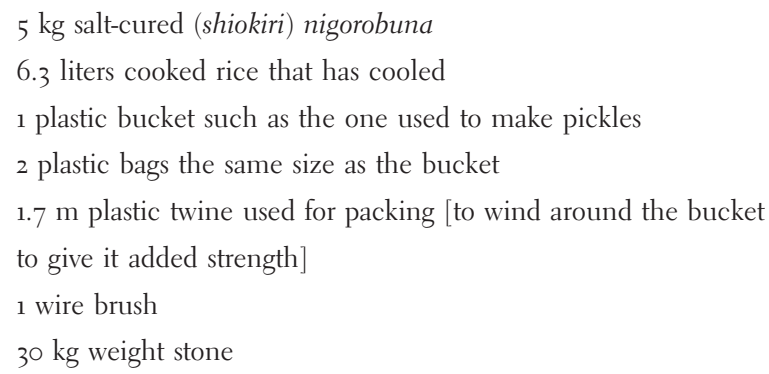

Wash the salt-cured fish to remove the salt. Use a wire brush to remove the scales as if you were polishing the fish; then wash the fish well. Drain the fish for several hours to allow them to dry. Line the plastic bucket with both of the plastic bags and then place the rice and fish together inside. Close first one bag then the other. Wrap the plastic rope around the bucket [to give it strength] and put on the lid. Place the heavy stone on top of the lid. (Hashimoto 2016: 274)

As noted earlier, nigorobuna is the variety of crucian carp preferred for funazushi. The fish chosen for funazushi are about the length of a hand and ideally should weigh between 300 and 400 grams (Shiga no Shoku Bunka Kenkyūkai 2011: 15-16). Crucian carp carry their eggs in March and April, which is when they are caught for funazushi since the female fish are preferred for their roe.

The recipe specifically calls for shiobuna, which refers locally to nigorobuna that have been cured in salt. Notes to the recipe suggest that the shiobuna can be purchased from a fish seller, but they can also be prepared at home. The purpose of the salt curing is to remove the moisture from the fish. Shiobuna are made by first removing all of the internal organs of the fish except for the roe. Then the fish are doused with salt and packed in a bucket with more salt for a period of several months. The bucket has a heavy stone placed on top of a lid that sits on top of the contents of the bucket. The stone weight is to force the lid down on the contents of the bucket, thereby pressing out any moisture.

If the carp is salted in April, it can be cured by July or August to make funazushi, which is said to be the best time 
to make the dish (Hibino 1999: 29). The sushi is ready to be eaten three months later if the bucket is placed in a sunny spot. After six months any bones remaining in the fish are soft enough to eat (Figure 1).

The previous recipe is a dry version of funazushi. Other recipes, such as the early modern version cited earlier, call for water to be added to the bucket. The water acts as a barrier to prevent oxygen interacting with the ferment, which could inhibit the anaerobic lactic acid fermentation. Instead of water, the recipe above uses plastic bags to seal the fermenting materials, and it is supposed to result in a funazushi that does not produce a foul smell while it is fermenting (Hashimoto 2016: 275). Funazushi recipes can have many other variations such as in the amount of salt used, the variety of rice, the degree to which the rice is cooked, and the period that everything is allowed to ferment (Fujita 2009).

At the end of the fermentation process, the rice loses its granularity and has the consistency of a thick porridge. Having served as the medium for the fermentation, the rice has lost any sweetness and is the most sour and gamey portion of the funazushi, which is why many people who eat funazushi will not eat the rice. Some recipes for funazushi replace the rice partway through the fermentation process to make it more palatable (Hibino 1999: 63; Shinoda 2002: 22-23). One early nineteenth-century recipe for funazushi suggested that the best way to enjoy the dish was to discard the rice used to prepare the sushi and replace it with freshly cooked rice that had been allowed to cool (Sugino 1985: 269).

\section{Funazushi Tasting Notes}

Books acquainted me with the history and process of making funazushi, but only hinted at the taste, if they mentioned it at all. To remedy my lack of knowledge, during a 2019 research trip to Japan, I allocated two days in Shiga Prefecture with the goal of eating as much funazushi as possible. Given that I understood that the taste of funazushi could vary depending on who made it, I wanted to be sure to be able to identify fully the gustatory qualities of the dish. In two days, consuming funazushi with almost every meal, I felt that I had enough of the fermented food.

My base of operations was the city of Ōmihachiman, an important mercantile center from the early modern period, and a place identified in a book about local sushi as having several representative varieties of funazushi (Nōsan Gyoson Bunka Kyōkai 2002). However, when I arrived in Ōmihachiman and asked at my hotel where I could purchase funazushi, I was only directed to one high-end restaurant, which I wanted to avoid because I worried whether I could afford it. Fortunately, a map of farmers' markets indicated several that sold funazushi, so I walked three kilometers to the outskirts of town to one of these. The farm stand sold vegetables and other local foods, and in a refrigerator was a single whole funazushi. Uncertain as to whether I would ever find such a prize again, I purchased it for $¥ 2000$ (about \$18), and walked three kilometers back to my hotel to place it in the refrigerator in my room.

I need not have worried about never seeing funazushi again, because in exploring some of the tourist sites in Omihachiman, it quickly became apparent that there were

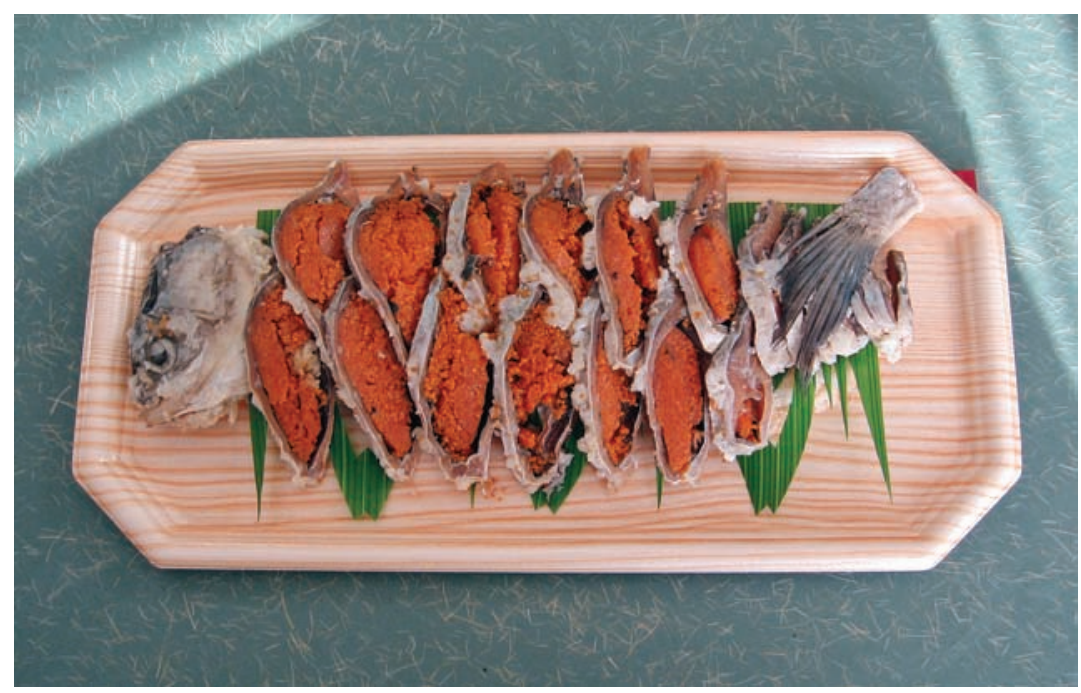

FIGURE 1: Funazushi with roe.

PHOTOGRAPH BY ERIC C. RATH (C) 2019 
many opportunities to buy funazushi in pre-sliced packages for sale. I purchased one of these packets from a vendor near Hachiman Shrine, the religious institution that gives the town its name (Figure 2). That package of sliced funazushi was only $¥ 700$ (about \$6). Having explored Ōmihachiman, I took the train north along Lake Biwa to Nagahama where a friend, Japanese local food expert Greg de St. Maurice, told me several stores sold funazushi near the train station. There I was able to spend just $¥ 330$ (about \$3) for a small package of slices, half the price of the previous one since this was a male fish and the slices lacked the orange roe. Fully stocked with samples, I returned to the hotel.

Faced with three different packages of funazushi, I opted to put aside the whole fish, not knowing how I would cut and eat it in my hotel room. I turned first to the $¥ 700$ package I had purchased near the shrine. The label indicated it was made by Kawada Shōten of Ōmihachiman. Flavorful funazushi is often said to be best enjoyed with sake, and a local sake from Shiga Prefecture, Matsutsukasa, was recommended to me. However, for this initial tasting, I opted for Asahi Super Dry Beer, available from the hotel's vending machine.

When I purchased the sushi from the seller, he said that if I liked blue cheese I would like funazushi. Roquefort was the immediate smell that hit me when I opened the package. The same seller also told me that the fish would be fine without refrigeration, and I had carried it around with me for several hours. When I smelled the fish, I worried that it had continued to ripen.

With my open can of beer on hand, I tried a small piece filled with the orange roe with a little of the rice underneath. The blue cheese bouquet carried through in the initial taste, but then a wave of sourness hit me strong enough to make my lips pucker and to turn my head in a grimace. It was like biting into a strange, extremely sour candy but one without any trace of sweetness. The flesh of the fish proved quite chewy, but the roe fell apart in my mouth. The mouthfeel of the rice was pure paste. A sharp cheddar cheese taste lingered in my mouth along with a discrete saltiness that made me glad for the beer.

I next sampled the male funazushi that I had purchased in Nagahama. According to the label, this was also made in Ōmihachiman by a company named Nōson Tsukudani. Lacking the roe, I could concentrate on the flesh of the fish. The thin slices had a texture and taste more reminiscent of prosciutto than blue cheese. The rice was saltier and more sour, and trying that again caused a physical reaction,

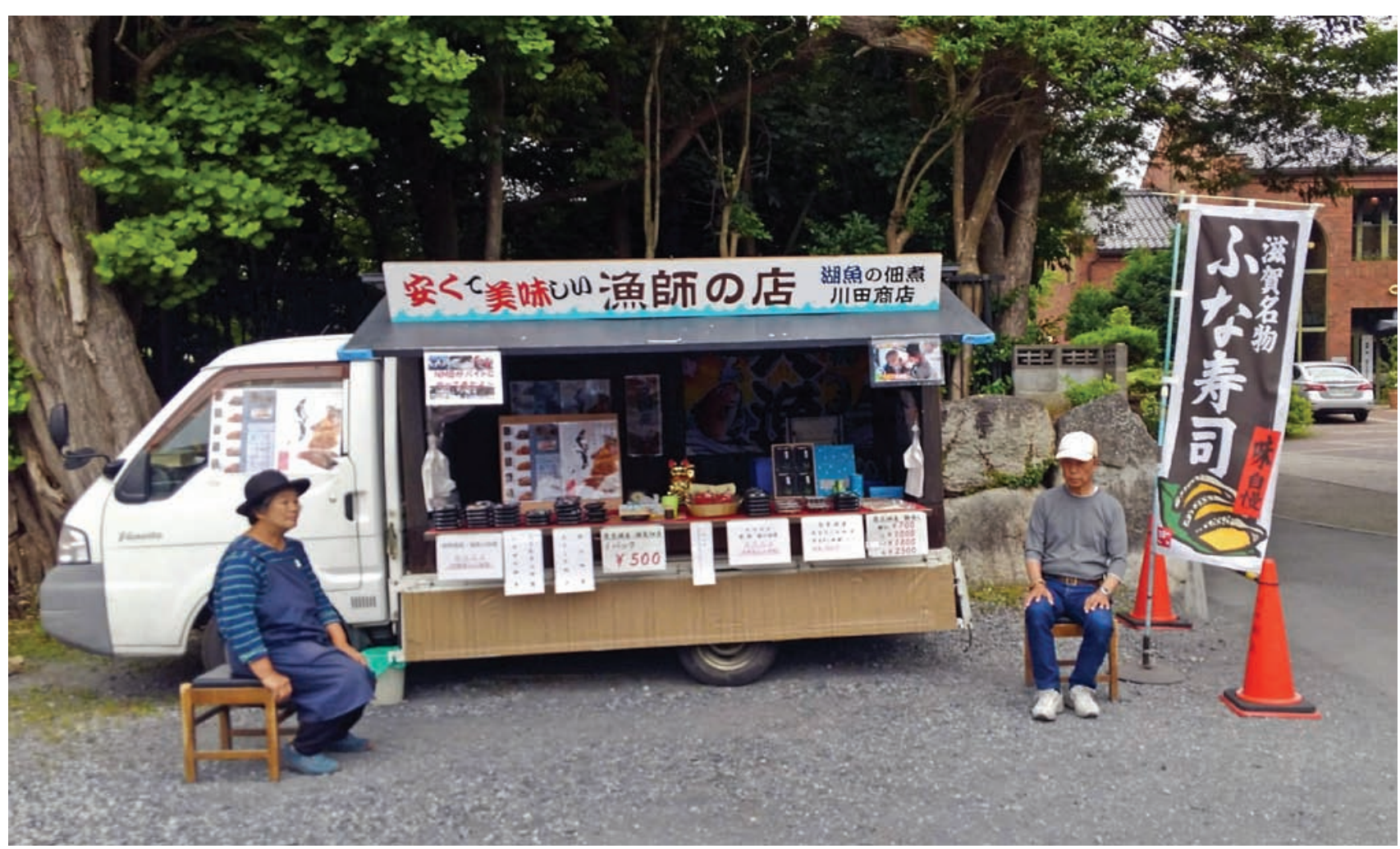

Figure 2: Funazushi vendors near Hachiman Shrine, Ōmihachiman City, Shiga Prefecture, June 2019.

PHOTOGRAPH BY ERIC C. RATH (C) 2019 


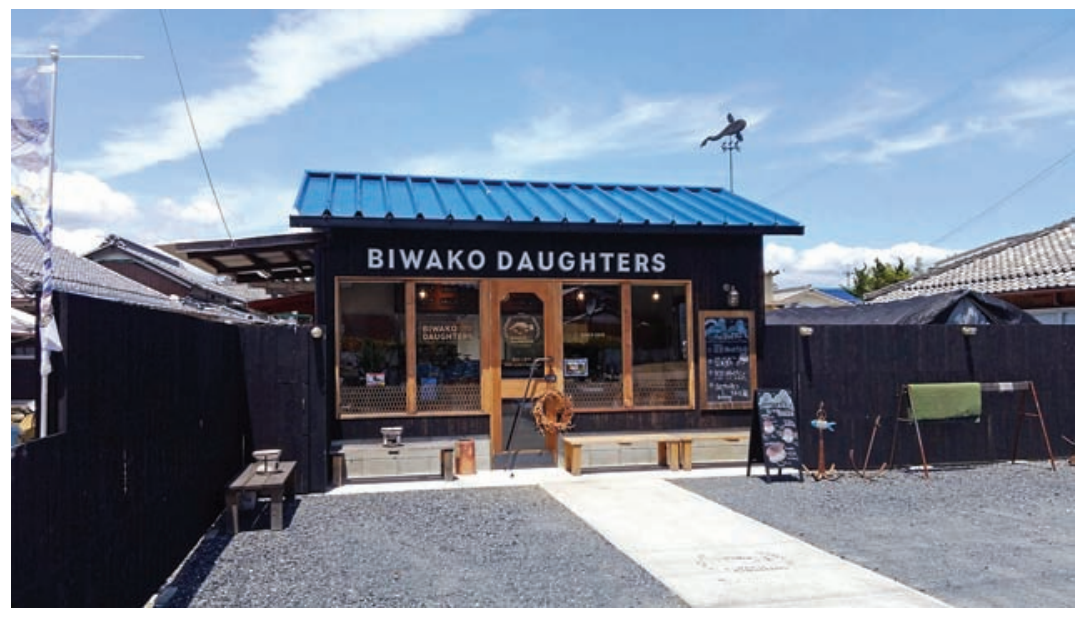

FIGURE 3: Biwako Daughters restaurant.

PHOTOGRAPH BY ERIC C. RATH $(2) 2019$

twirling my tongue and turning my head. I had planned to spend some money and visit the expensive sushi restaurant to try its funazushi for dinner, but having consumed two fish along with my beer, I was too full.

The taste of funazushi lingered in my mouth the next day. The sourness at the back of my mouth sometimes reminded me of the bitterness of instant coffee and at other moments called to mind the taste of a dry heave, that point brought on by vomiting from a hangover when one has thrown up all the contents of one's stomach including the stomach acid and phlegm. Except when being hung over, I had managed to avoid that taste in my mouth, and it was not one that I wanted to experience again.

Funazushi evoked for me notes of cheese and aged ham, but it was not until I visited the restaurant Biwako Daughters the next day that I discovered how these tastes could be used to maximum effect. Biwako Daughters is a small restaurant near Lake Biwa and between the Yasu and Ōmihachiman train stations and it has been open for about two years (Figure 3). The restaurant sells funazushi and other fish products made according to traditional methods, but they have taken these recipes in new directions, and one of these is the funazushi sandwich. The funazushi sandwich, which sells for $¥ 1000$ (around \$9), takes a slice of funazushi and pairs it with a creamy Havarti cheese on crunchy Italian bread. One bite of this and I was transported to Tuscany where I discover a specialty sandwich that the Italians have hidden from the rest of the world. The thin slice of funazushi carries three times the taste of prosciutto, but without any oiliness, fishy or otherwise. The proprietor of Biwako Daughters, Nakagawa Tomomi, recommended trying half the sandwich as is and the other half toasted with olive oil (Figure 4). The toasting made the bread even crispier, melted the cheese, and blended the flavors. But even untoasted the bread provided a neutral palette for enjoying the sushi, which lost all its sourness when I ate it that way. I had a happy feeling in my mouth.

The sourness of funazushi rice came into play in another dish served at Biwako Daughters, black meron bread with a cream filling (Figure 5). Meron bread is a soft dough confectionery found in bakeries throughout Japan characterized by a cookie top that is usually baked to a golden brown. Squares drawn across the cookie dough top further the impression that the bread emulates a musk melon, and that is probably how the sweet got its name. The black version of meron bread adds cocoa, and it is made by Ichiseipansho Bakery in Ömihachiman, where Biwako Daughters purchases its baked goods. Nakagawa sliced the bread in half, and added cream in the middle. The cream had a lemony taste thanks not to any citrus but to a spoonful of funazushi rice mixed in that imparted a citrus taste without any sourness.

Biwako Daughters' adaptations extend also to sandwiches made with black bass, sweetfish (ayu), and eel. According to Nakagawa, the sandwiches offer a way for customers to try these fish-funazushi especially-in a form that they are more familiar with. While Japanese cuisine is usually presented as being synonymous with rice, per capita rice consumption in Japan is half of what it was fifty years ago, and the transition in diet toward other grains is evident in Shiga not just in the Biwako Daughters' menu but in the prominence of wheat fields that have replaced rice paddies in the prefecture. In 2013, Shiga Prefecture ranked fourth nationally in terms of wheat production according to the Ministry of Agriculture, Forestry and Fisheries (Statistics Japan 2019). 
That evening I tried a whole funazushi (¥1000) from Biwako Daughters, which I paired with a local sake (Aichi Shuzō's Tomitsuru Tokubetsu Honjōzō, 60 percent seimaibuai indicating that 40 percent of the rice had been milled away in processing, which made the sake a step above an ordinary one). Nakagawa indicated that her family followed local custom, catching the crucian carp in February or March, cleaning and salting them and putting them aside until July or August to make funazushi. But besides rice and salt, their family recipe mixed in some lees left over from sake making with the rice to facilitate fermentation. Their funazushi retained a slight sake aftertaste and the sushi had a meatiness reminiscent of summer sausage. The sourness remained in the fish and the rice, but it was less prominent than in the other examples I had tried. The rice underneath was smooth and also less salty than other examples. However, that sour taste proved cumulative; and despite the sake, which was dry enough to stand up to the funazushi, I still longed for a baguette. I found that I could only eat about two-thirds of the fish, not including the head and tail. For dinner, I had once again planned to visit the upscale sushi restaurant, but I found that I could not eat anything more that day.

The next morning, faced with having to check out of my hotel, I could no longer delay deciding what to do with the whole funazushi in my room refrigerator. So I brought it to breakfast and asked someone in the kitchen to cut it for me. I received a small plate of the funazushi presented on top of the rice, but in much thicker slices, which helped reinforce a mouthfeel and taste like summer sausage. The thicker slices also made the fish much chewier and harder to eat. Perhaps because I was becoming used to funazushi or that I could pair the sushi with other items from the breakfast buffet, I only experienced a slight shudder from the sour taste. I managed to eat all but four slices, the tail and head. Telling myself it would be a long time before I could have

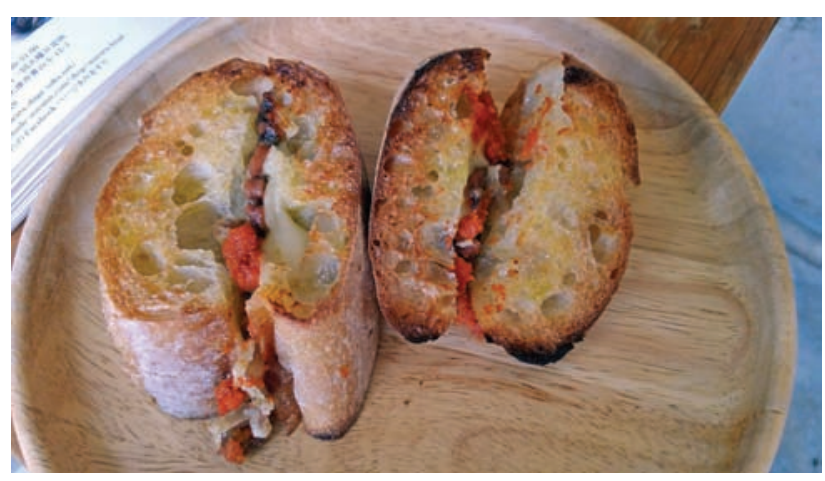

FIGURE 4: Grilled funazushi sandwich.

PHOTOGRAPH BY ERIC C. RATH (C) 2019 funazushi again, I tried to finish it. I ate one more slice, gagged, and had enough. I offered the rest to the kitchen staff in case they wanted some of their local delicacy.

My reaction to funazushi, I think, was due to having too much of a good thing. Funazushi, as I was told, was best meant as an accompaniment to alcohol. It was not meant to be a meal in and of itself as I had consumed it. Traditionally, in Shiga Prefecture funazushi was reserved for special occasions as opposed to being a daily food (Shiga no Shoku Bunka Kenkyūkai 2011:12). It is no wonder that the taste of funazushi lingered with me given that it was a main part of my diet while I was in Shiga.

\section{Funazushi and the Possible Future of Sushi}

Funazushi is often described as an ancient form of sushi, but it might also represent a possible future for sushi. Beloved seafood used in conventional sushi including yellowtail, yellowfin tuna, eel (unagi), sea urchin, and above all bluefin tuna have been captured to the point that their populations are threatened. Conscientious sushi eaters should avoid or strictly limit their consumption of these unless they are sure that these marine products are sourced sustainably. ${ }^{1}$ Instead of dining on endangered species, sushi lovers should reconsider fish that were once synonymous with sushi, namely carp, which are plentiful. In fact, there is a population explosion of four varieties of carp that were introduced to the United States forty years ago to combat weeds and parasites in aquatic farms and canals. The bighead carp (Hypophthalmichthys nobilis), black carp (Mylopharyngodon piceus), grass carp (Ctenopharyngodon idella), and silver carp (Hypophthalmichthys molitrix) - known collectively as Asian carp-are crowding out native fish in the Mississippi River and other waterways to the point that they have been labeled "invasive" and a "nuisance species." Even the Sierra Club calls them the "most hated fish on the Mississippi" (Upholt 2018).

Asian carp are edible, low in fat, and indeed might be safer to eat than larger, predatory fish like fatty bluefin tuna since the carp are vegetarian, are generally not bottom feeders, and do not have the higher levels of mercury found in large fish that subsist on smaller ones. However, Asian carp has a negative image in the United States beyond simply being "invasive" and a "nuisance." Silver carp, which can weigh up to go pounds, can leap ten feet out of the water when they hear boat engines, striking and injuring boaters. Despite their size, which can range from 90 to 150 pounds, "Asian carp" may sound too close to the carps' relative, the ornamental goldfish, something only consumed live by drunken fraternity pledges decades ago. Common carp (Cyprinus carpio) in the United States are also 
considered a "trash fish," and the word carp itself in English is synonymous with finding fault (Keevin and Garvey 2019: 1-2).

In response, savvy marketers have relabeled the Asian carp as "Kentucky white fish" and "silver fin" in the same way that dolphinfish (Coryphaena hippurus) became mahi-mahi to calm consumers worried that they were eating actual dolphins. Such a move also removes the designation of "Asian," which some may find offensive when applied to a "hated" variety of fish. Government agencies are trying to encourage consumption of Asian carp. In 2019 the Illinois Department of Natural Resources launched a grant program to defray the cost of marketing for businesses making food products out of Asian carp (AsianCarp.US 2019). Chef Philippe Parola, who has for decades promoted the consumption of alligator and nutria ("river rats") in Louisiana, operates a website called "Eat the Problem" that educates consumers about Asian carp and sells fishcakes made with silver fin, which the website presents as "the only viable solution to managing the rapidly expanding Asian carp population throughout America" (Eat the Problem 2019). In blind taste tests, consumers preferred bighead carp two to one over tilapia and catfish prepared the same ways (Keevin and Garvey 2019: 3).

Support of interest to use Asian carp as a food source could dovetail with the growing popularity of fermented foods as well as a long-standing love of sushi to encourage someone to try making fermented Asian carp sushi in North America. A survey of menus and sales from nine thousand restaurants found that in 2018 orders for fermented foods were up 149 percent and fermented foods were expected to continue to trend among consumers (Everett 2019). Fermented sushi could attract customers who are turning to once-exotic kefir, kombucha, and kimchi in greater numbers for their health benefits. Year-old sushi might sound off-putting, but the flavors of cheese and cured meat are familiar ones to the North American palette. Funazushi has a meaty/dairy taste profile without the nitrates and saturated fats found in processed meats and cheeses.
In 1966, one food writer introduced sushi to Western audiences as a "rice sandwich," so perhaps it is time to rethink the possibility of a sushi sandwich made using bread instead of rice (Keys 1966: 136). For people in the American Midwest, rather than eating imported and endangered bluefin tuna or meat and cheese laden with cholesterol, it makes more sense to try to make a local sushi with a fish that is overabundant in nearby rivers. In other words, in the Anthropocene Age of diminishing natural resources, global warming, and concerns about fossil fuel use, rather than import threatened seafood from halfway around the globe from Asia, it would be far better for Americans to search for our own local "Asian" fish and make them the basis for our sushi. Preparing sushi with a 9o-pound silver fin might be a challenge, but not an insurmountable one.

Living in the Midwest far from the oceans, I generally avoid the conventional sushi available here unless it is vegetarian or I know how and when the seafood was sourced and trust the chef. So, I am waiting and hoping for someone to make Asian carp funazushi. I imagine them slicing the sushi thinly and serving it with cheese from Iowa on Italian bread made from Kansas wheat or gluten-free sorghum. I would wash away any sourness with my favorite beer from Missouri or Colorado. Let me be the first to try a sushi sandwich made with local Asian carp. @

NOTE

1. The Monterey Bay Aquarium publishes a free Seafood Watch Sushi Consumer Guide available at www.seafoodwatch.org, and it has a free phone app to assist consumers in purchasing sustainable fish and avoiding varieties that are overfished.

\section{REFERENCES}

AsianCarp.US. 2019. "Illinois Department of Natural Resources Launches the Market Value Grant Program," March 14. www. asiancarp.us (accessed 13 June 2019).

Eat the Problem. 2019. www.eattheproblem.us (accessed 5 September 2019).

Everett, Holly. 2019. "Restaurant Menu Trends: What to Expect to See on More Menus in 2019." Upserve Restaurant Insider. https://upserve.com (accessed 5 September 2019).

Fujita, Chieko. 2009. "Funa Zushi." Tokyo Foundation. tokyofoundation.org (accessed 9 May 2012).

Hashimoto Michinori, ed. 2016. Saikō funazushi no rekishi. Hikone, Shiga: Sunraizu Shuppan.

Hayakawa Hikari. 2009. Nihon ichi Edomaezushi ga wakaru hon. Tokyo: Bungeishunsha.

Hibino Terutoshi. 1997. Sushi no kao: Jidai ga motometa aji no kakumei. Tokyo: Taikōsha.

- 1999. Sushi no rekishi o tazuneru. Tokyo: Iwanami Shoten.

Hosking, Richard. 1996. A Dictionary of Japanese Food: Ingredients and Culture. Rutland, VT: Charles E. Tuttle.

Huang, Hsing-Tsung. 2000. Science and Civilization in China, vol. 6, Biology and Biological Technology, Part V: Fermentation and Food Science. Cambridge: Cambridge University Press.
FIGURE 5: Black meron bread with funazushi cream.

PHOTOGRAPH BY ERIC C. RATH (C) 2019 
Issunsha, ed. 1985. Gōrui nichiyō ryōrishō, vol. 1 of Nihon ryōri hiden shūsei: Genten gendaigoyaku, 95-217. Kyoto: Dōhōsha.

Keevin, Thomas M., and James E. Garvey. 2019. "Using Marketing to Fish-down Bigheaded Carp (Hypophthalmichthys spp.) in the United States: Eliminating the Negative Brand Name, 'Carp'." Journal of Applied Ichthyology 35(5): 1141-46.

Keys, John D. 1966. Japanese Cuisine: A Culinary Tour. Tokyo: Charles E. Tuttle.

Matsushita Sachiko. 1996. Zusetsu Edo ryōri jiten. Tokyo: Kashiwa Shobō.

McGee, Harold. 2004. On Food and Cooking: The Science and Lore of the Kitchen, Completely Revised and Updated. New York: Scribner.

Nōsan Gyoson Bunka Kyōkai, ed. 2002. Sushi narezushi, vol. 1 of Kikigaki furusato katei ryōri. Tokyo: Nōsan Gyoson Bunka Kyōkai.
Ōkawa Tomohiko. 2008. Gendai sushigaku sushiology: Sushi no rekishi to sushi no ima ga wakaru. Tokyo: Asahiva Shuppan.

Okumura Ayao. 2002. "Kaisetsu." In Sushi narezushi, vol. 1 of Kikigaki furusato katei ryōri, ed. Nōsan Gyoson Bunka Kyōkai, 235-53. Tokyo: Nōsan Gyoson Bunka Kyōkai.

Shiga no Shoku Bunka Kenkyūkai, ed. 2011. Funazushi no nazo, shinsōban. Hikone, Shiga: Sunraizu.

Shinoda Osamu. 2002. Sushi no hon. Tokyo: Iwanami Shoten.

Statistics Japan. 2019. www.stats-japan.com (accessed 13 June 2019). Sugino Gonuemon. 1985. Meihan burui, vol. 9 of Nihon ryōri hiden shūsei: Genten gendaigoyaku, ed. Issunsha, 211-72. Kyoto: Dōhōsha.

Upholt, Boyce. 2018. "Eating the Most Hated Fish on the Mississippi." Sierra, The National Magazine of the Sierra Club, November 12. sierraclub.org (accessed 5 September 2019). 